\section{Conclusion}

The Nuffield Advanced Physics course has been developed over the last four or five years. At the time of writing, the publications are still emerging from the press, and it is too soon to give any account of their reception. So the course is still in its infancy. Those of us who were associated with it, while hoping that the infant is healthy, also hope that it will grow and develop. The last thing we wish to see is adoption of the course in a static and unchanging way, so that the course becomes a new orthodoxy, and a sad case of arrested development. Its future, however, is not now in our hands, but in those of teachers, whose creative efforts are needed to give it life.

\section{Acknowledgments}

Figure 1 is from Nuffield Advanced Physics, Teachers' Handbook, (Penguin Education, 1972)

The publisher is Penguin Education and further information may be obtained from: Penguin Education, Harmondsworth, Middlesex, UK Figure 2 is from photography by M. Plomer.

\title{
HORIA HULUBEI
}

On 22 November 1972, there ended the meritorious activity, which had gained the recognition of the entire scientific world, of Horia Hulubei, the President of the Romanian National Committee of Physics, scientist of worldwide renown, who died, leaving deep regret not only with those who had the privilege of knowing him but also with the new generation of Romanian physicists.

As words can only dimly evoke a personality so outstanding as that of Horia Hulubei's, we shall confine ourselves to the facts.

Horia Hulubei was born on the 15 November 1897 in lasi where he attended high school and university. In 1926, after taking his degree in physics and chemistry, he left for Paris to obtain his doctorate at the Sorbonne where he joined the group headed by the new Nobel prize winner, Jean Perrin, and where he remained, with brief interruptions, until 1938.

There, in the company of the great names of French physics : Jean Perrin, Marie Curie, Paul Langevin and Aimé Cotton, Hulubei's scientific personality took shape as he established himself as an original researcher. His works, regarded as classical, on Raman effect upon water, the Cauchois-Hulubei spectrometer which exceeded in sensitivity all existing X-ray spectrographic methods and which afforded elaboration of the well-known tables of wavelengths, the recording of the multiple Compton effect as well as the X-lines of the elements 87 and 93, were only a few of his investigations.

$\mathrm{He}$ returned to Romania in 1938. Because of the Second World War which prevented him from continuing his laboratory research, he devoted himself to academic work. He held, at Bucharest University, the Chair of Physical Chemistry subsequently transformed into the Chair of Atomic Physics.

Soon his activity was considerably expanded. As Director of the first Institute for Physics and then of the Institute for Atomic Physics in Bucharest, as well as President of the Committee for Nuclear Energy, he made an invaluable contribution to the development of physics in Romania and to the formation of new generations of physicists. With his unerring competence, hard to overestimate, he co-ordinated the investigations of complex teams of researchers in new fields, such as high energy physics, reactor physics or nuclear reactions, and he militated, without respite, for the stimulation of wide collaboration between physicists to ensure a continuous flow of information and ideas.

$\mathrm{He}$ was elected member of the Academy of the Romanian Socialist

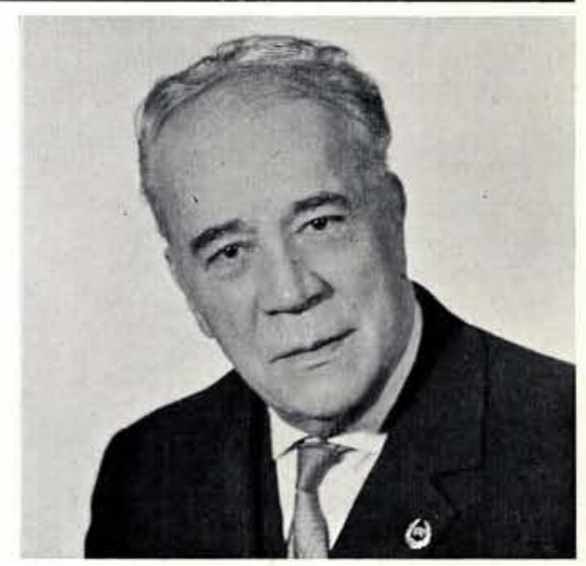

Republic, the French Academy of Sciences, the Academy of Science of Portugal, the Academy of Science of New York, and other scientific societies.

Full of vitality up to the last moments of his life, he took an active part in the World Peace Council, in the Conferences for Nuclear Energy (Geneva), in the scientific councils of the Joint Institute for Nuclear Research in Dubna, as well as in the activity of the International Agency for Atomic Energy, where he played a leading role as Governor, and VicePresident of the Governors' Council.

Paving the way to the development of the most advanced branches of physics, Horia Hulubei appears in perspective as the real founder of modern physics in Romania.

Submitted by the Romanian National Committee of Physics.

\section{Nuclear Physics}

\section{June - 1 July 1972, Aix-en-Provence, France}

The Nuclear Physics Division of EPS held its first large conference from 26 June-1 July in the pleasant surroundings of Aix-en-Provence. The conference was mainly organized by the French Physical Society and was dedicated to the memory of Claude Bloch who died in December 1971 and who had a major influence on post-war French theoretical nuclear physics.

In order that the conference should cover a wide area of nuclear physics while remaining a reasonable size, the programme was centred around three topics, emphasizing different but complementary aspects of the nucleus. The three topics were : I Fission, II Nuclear spectroscopy with heavy ions, III Nuclear physics above $100 \mathrm{MeV}$. There were main invited talks in each of these fields and the conference broke up into parallel sessions for shorter contributed papers in each field. In its format the confer- ence was successful in bringing together what have tended to become somewhat separated areas of the subject.

Fission has in the past been a separate part of nuclear physics. The fission isomers and their explanation in terms of the double hump potential barrier have brought fission back into the main stream of nuclear physics particularly through the predictions of the double hump from the Strutinski synthesis of the microscopic shell model and the macroscopic liquid drop model. Claude Bloch at the time of his death was 
involved on work showing how the details of fission are dominated by shell effects and this work was described in a talk by R. Balian. Some of the ways fission is contributing to the main stream through the spectroscopy of the shape isomers were discussed by $\mathrm{S}$. Bjornholm. One of the highlights of the fission contributions was the experiment carried out at Munich in which the E2 internal conversion lines of the ground state rotational band of the shape isomer have been observed and show the expected larger moment of inertia.

It was the calculations of the nuclear potential energy surface which led to the speculations on super heavy elements and the possibility of their formation in heavy ion reactions. Swiatecki, in a talk linking fission and heavy ion reactions, emphasized the relevance of the information obtained on the shape of the nuclear potential energy surface to the possibility of formation of super heavy elements and the critical need for knowledge of nuclear viscosity.

A different approach to the nucleus is involved in the remaining topic covered by the conference - nuclear physics above $100 \mathrm{MeV}$, in which high energy projectiles or mesons are used to probe the fine structure of nuclei. It is from these experiments, as Wilkinson emphasized in a closing talk, that we are getting evidence that the nucleus really is made from neutrons and protons. There were contributions showing the effect of the 3-3 resonance in pion-nucleus scattering and in photo-meson production in nuclei, but the inelastic electron scattering and the $p, 2 p$ experiments which reveal the low-lying bound levels still appear to disagree on the position of the lowest s level.

This conference showed that heavy ion and high energy approaches to the nucleus are beginning to take us away from the traditional preoccupation with light ion reactions and the few nucleons at the top of the Fermi sea. It was successful and timely in bringing together these developing fields and in highlighting areas where, with appropriate facilities, our understanding of the nucleus will be enriched.

\section{Physics of Semiconductors}

\section{5-29 July 1972, Warsaw, Poland}

The International Conference on the Physics of Semiconductors was held in Warsaw, 25-29 July 1972, as the eleventh in the series of biannual international conferences, which are supposed to summarize two-year periods in the development of semiconductor physics.

The conference was organized by the Institute of Physics of the Polish Academy of Sciences together with the University of Warsaw and sponsored by the International Union of Pure and Applied Physics.

The organizers received more than 450 contributed papers, of which they could accept less than one-third. The invited speakers and subjects were chosen on the basis of suggestions sent to us by the members of both the International and the Polish
Programme Committees. The seven plenary invited papers should give some idea of what, we felt, are the most important subjects in the current development of semiconductor physics. A.L. Efros of loffe Institute in Leningrad spoke on Low Temperature Conductivity of Strongly Compensated Semiconductors, T. Kasuya of Thoku University in Sendai on New Aspects of the Electronic Properties of Magnetic Semiconductors, W. Paul of Harvard University on Current Status of Some Basic Problems in Amorphous Semiconductors, I. Solomon of Ecole Polytechnique in Paris on Spin-Dependent Properties of Semiconductors, D.C. Tsui of Bell Laboratories on Quantum Eifects in the Semiconductor Surface Layer, and W. Zawadzki of the Institute of Physics in Warsaw on Electron Scattering and Transport Phenomena in Small-Gap Semiconductors.

The conference was attended by more than 600 participants. Among the biggest delegations were : Poland 110 , USA and USSR - 80 each, France and German Federal Republic - 50 each, Czechoslovakia and German Democratic Republic - 30 each, Great Britain and Japan - 25 each.

The general opinion was that the conference was a success. The participants complimented the programme, as being truly international and wellorganized both in time and in the choice of invited papers.

The next conference will be held in Stuttgart in 1974, and will be organized by Dr. O.G. Folberth, IBM Component Development Laboratory, Schönaicherstr. 220, D-703 Böblingen, Fed. Rep. of Germany.

\section{J. Kolodziejczak}

\section{ESSDERC 1972}

\section{1-15 September 1972, Lancaster, UK}

The Second European Solid State Device Research Conference was held at the University of Lancaster, England, from 11-15 September 1972, and was attended by over 300 scientists from 19 countries. This series of conferences has become established by combining the German and British meetings on the same topic, and like them features a small number of invited lectures and a large number of ten-minute contributed papers. This year the invited talks were by E. Ash (Integrated Optics), M. Bernard (NonLinear Optical Susceptibilities), J. Collins (Ferrimagnetic Film Microwave
Devices), W. Merz (Ferroelectric Applications), E.G.S. Paige (Acoustic Surface Wave Devices) and H. Queisser (Semiconductors in the Relaxation Regime). All reached an unusually high standard, but Hans Queisser's contribution must be singled out as exceptional. A stranger entering the hall during the applause at the end might well have thought that a US Presidential candidate was being nominated! The talk was concerned with the behaviour of semiconductors when the carrier lifetime was shorter than the dielectric relaxation time, a condition that causes most of our standard assumptions to become invalid, and that turns conventional teaching on its head. One feature of the other invited talks that aroused some comment was the avoidance of semiconductor topics. Most solid state device conferences in the past have been heavily weighted towards semiconductors, and it was interesting to note how so many other areas are now proving ripe for exploitation. A special evening discourse by $W$. Shockley on the early history that lay behind the invention of the transistor entertained a large audience. For an hour or so, they were taken back twenty-five years, and treated to a well-prepared and documented exposition, bringing in characters familiar and unfamiliar, and tracing their subsequent fates. 